\title{
Validation of claims data to identify death among aged persons utilizing enrollment data from health insurance unions
}

\author{
M. Sakai ${ }^{1,2,3^{*}} \mathbb{B}$, S. Ohtera ${ }^{1,2}$, T. Iwao ${ }^{2}$, Y. Neff ${ }^{1,2}$, G. Kato ${ }^{4}$, Y. Takahashi ${ }^{1}$, T. Nakayama $^{1}$ and on behalf of BiDAME (Big \\ Data Analysis of Medical care for the Elderly in Kyoto)
}

\begin{abstract}
The identification of death is critical for epidemiological research. Despite recent developments in health insurance claims databases, the quality of death information in claims is not guaranteed because health insurance claims are collected primarily for reimbursement. We aimed to examine the usefulness and limitations of death information in claims data and to examine methods for improving the quality of death information for aged persons.

We used health insurance claims data and enrollment data (as the gold standard) from September 2012 through August 2015 for nondependent persons aged 65-74 years enrolled in Japanese workplace health insurance. Overall, 3,710,538 insured persons were registered in the database during the study period. We analyzed 45,441 eligible persons. Inpatient and outpatient deaths were identified from the discharge/disease status in the claims, with sensitivities of $94.3 \%$ and $47.4 \%$, specificities of $98.5 \%$ and $99.9 \%$, and PPVs of $96.3 \%$ and $95.7 \%$, respectively, using enrollment data as the gold standard. For outpatients, death defined as a combination of disease status and charge data for terminal care still indicated low sensitivity (54.7\%).

The validity of death information in inpatient claims was high, suggesting its potential usefulness for identifying death. However, given the low sensitivity for outpatient deaths, the use of death information obtained solely from records in outpatient claims is not recommended.
\end{abstract}

Keywords: Aged, Health insurance claims, Sensitivity, Specificity, Validation

\section{Introduction}

In Japan, an ultra-aging, high-mortality society, $33.0 \%$ of the population, were $\geq 60$ years old in 2017 [1]. Deceased persons in Japan comprised approximately $1,200,000$ in 2014; this is estimated to increase to approximately 1,670 , 000 by 2040 [2]. In constructing a sustainable end-of-life care system, several challenges for research have emerged, surveying mortality and medical care practice for aged persons at the end of life [3-5]. Thus, the identification of

\footnotetext{
* Correspondence: sakai.michi.7v@kyoto-u.ac.jp

'Department of Health Informatics, Kyoto University School of Public Health, Yoshidakonoe-cho, Sakyo-ku Kyoto 606-8501, Japan

${ }^{2}$ Division of Medical Information Technology and Administration Planning, Kyoto University Hospital, 54 Kawahara-cho, Shogoin, Sakyo-ku Kyoto 606-8507, Japan

Full list of author information is available at the end of the article
}

death is critical for epidemiological research targeting aged persons.

Recent developments in the health insurance claims databases of government agencies and the private sector have transformed epidemiological research in Asia-Pacific countries [6-12]. In Japan, private companies have created health insurance claims databases for research. The National Database of Health Insurance Claims and Specific Health Checkups of Japan (NDB) that contains almost $100 \%$ of the digitized health insurance claims for the entire country was also constructed.

However, health insurance claims data are collected primarily for reimbursement, rather than for research following the patient prognosis. Thus, quality of death information in claims is not guaranteed. Previous study has examined the validity of death information recorded in claims using data in 2005-2009 and indicated that the sensitivity of death information in claims was low [13].

(c) The Author(s). 2019 Open Access This article is distributed under the terms of the Creative Commons Attribution 4.0 International License (http://creativecommons.org/licenses/by/4.0/), which permits unrestricted use, distribution, and reproduction in any medium, provided you give appropriate credit to the original author(s) and the source, provide a link to the Creative Commons license, and indicate if changes were made. The Creative Commons Public Domain Dedication waiver (http://creativecommons.org/publicdomain/zero/1.0/) applies to the data made available in this article, unless otherwise stated. 
However, to date, a method to improve the validity of death information in claims has not been established. Currently, validation studies using the latest claims database are underway [14]. As part of this effort, we aimed to examine usefulness and limitations when using death information in claims databases and to examine methods for improving the quality of death information for aged persons.

\section{Methods}

\section{Study design}

This cross-sectional study validated death information from health insurance claims against that recorded in enrollment data for the health insurance union from the same month (the latter serving as a gold standard). Because the claims data used in the present study did not include information on the date of death, the data were compared by month.

\section{Data source}

Claim validation requires the linkage of claims data and other sources of highly reliable data (gold standard). However, The Japanese Ministry of Health, Labor and Welfare (MHLW) prohibits linking data from NDB to external data. Hence, we utilized workplace health insurance's claims database which directly link health insurance claims and enrollment data at the individual patient level with high precision [15]. We used the claims database for insured persons enrolled in workplace health insurance unions that were available through a database vendor, Japan Medical Data Center Co., Ltd. This database contains monthly claims submitted to health insurance unions, particularly for those insured in Japanese health insurance unions for employees of large companies (union-managed health insurance). As of September 2015, these comprised approximately $10 \%$ of all Japanese beneficiaries. The database does not include the data of those enrolled in health insurance unions targeting mediumsized to small businesses, seamen, public employees, selfemployed individuals, and those covered by the Medical Insurance System for individuals aged $\geq 75$ years.

The data provided the discharge status for inpatient claims, with the following potential values: "continued," "cure," "death," "termination," and "transferred." Values reflect the status of healthcare provision: "continued" represents continued therapy; "cure" indicates that no further healthcare was needed due to complete cure or improvement; "termination" suggests that no healthcare will be provided at least for the time being; and "transferred" indicates that the patient was transferred to another hospital. The same information was also available as the disease status in the outpatient claims database.

The enrollment data recorded the month and year of the loss of insurance status as well as the reason for the loss of insured status ("retired, moved away, died, term expired, insurance premiums unpaid, transition, household separated, or other"). When an insured individual loses their insured status, the employer notifies the union, and this is reflected in the enrollment data.

\section{Study participants}

We included nondependent insured persons aged 65-74 years registered in the workplace health insurance's claims database between October 2012 and September 2015. We analyzed only nondependent insured persons to guarantee gold standard-level accuracy in death information from enrollment data. The insurance status for dependents is sometimes misclassified (in some cases, if the insured individual dies, the dependent of that insured individual is also registered as dead) and thus dependents are excluded from analysis. To conduct validation in a cross-sectional study design that would compare claims from the same month with enrollment data from the health insurance union, we excluded patients with missing information on health insurance union enrollment status (i.e., continued enrollment/loss of insured status) for the month of the most recent claim data (i.e., claims issued most recently). We also excluded any of those who lost their insured status with unknown reasons for the loss of insured status.

\section{Validation of death information that can be obtained from claims Claims-based definition of death}

We defined claims-based definition of death as patients for whom the discharge/disease status recorded in the most recent (last issued) claims was death (Definition 1). If multiple claims were issued in the same month, all claims were examined. If at least one claim noted death as the discharge/disease status, the patient was considered deceased. As we do not intend to develop a system by which health insurance associations confirm death from claims, we examined methods for increasing the validity of death information for outpatients by combining disease status and charge data recorded in claims. If two or more house calls or home visits are made within 14 days of death, a fee for terminal care can be charged for outpatients. Fees can also be charged when death certificates are issued at a patient's residence. We included these 2 charges for the definition of outpatient death to improve the validity. Definition 2 applied to patients for whom no claims were issued after a fee was charged for terminal care. Definition 3 applied to patients for whom no claims were issued after a death certificate was charged. Definition 4 applied to patients for whom the outpatient disease status was recorded as death or no claims were issued after a fee was charged for terminal care, or a death certificate was issued (i.e., Definition 1 or 2 or 3 ). 


\section{Gold standard definition of death from the enrollment data}

We defined the gold standard deceased patients as those for whom the loss of the insured status due to death was recorded in the health insurance union enrollment data. Patients, whose enrollment data listed the reason for the loss of the insured status as a cause other than death or were in a "continued" status, were not regarded as gold standard deceased patients.

\section{Defining true positives, false negatives, false positives, and true negatives}

True positives were defined as cases with any claimsbased definition of death (i.e., death information can be obtained from claims) and gold standard definition of death (i.e., the reason for the loss of the insured status in the enrollment data was recorded as death). False negatives were defined as cases with no claims-based definition of death but with a gold standard definition of death. False positives were defined as cases with any claims-based definition of death but not the case with the gold standard definition of death (i.e., the reason for the loss of the insured status in the enrollment data listed a cause other than death or was in the "continued" status). True negatives were defined as cases with no claims-based definition of death and no gold standard definition of death.

\section{Statistical analysis \\ Sensitivity, specificity, and positive predictive value}

We calculated the sensitivity, specificity, and positive predictive value (PPV) of our claims-based definitions of death for inpatients and outpatients separately. In the present validation, only claims issued in the most recent month for each patient were analyzed; thus, inpatients and outpatients were categorized based on claims issued in the most recent month. Inpatients were those who had received inpatient medical care during the most recent month of the issued claim (i.e., patients with $1+$ inpatient claims issued), and inpatient claims data were analyzed. Outpatients were those who only received outpatient medical care during the most recent month of the issued claim (i.e., those for whom only outpatient claims were issued), and their outpatient claims data were analyzed.

$\mathrm{R}$ version 3.2.4 was used for statistical analysis. Informed consent was not obtained because our study only used data that were anonymized in an unlinkable fashion (the data were anonymized using a method that does not leave a lookup table linking a patient with an assigned code or number to prevent the identification of specific patients). The study protocol was approved by Kyoto University's research ethics committee.

\section{Results}

\section{Patient characteristics}

Overall, 3,710,538 insured persons were registered in the database from October 2012 through September 2015. We analyzed 45,441 nondependent insured persons (43, 870 outpatients and 1571 inpatients), excluding 3,584, 302 persons aged $<65$ years, 56,130 dependents, 5743 persons with no health insurance claims, 13,370 persons with no data on health insurance union enrollment status (i.e., continued enrollment/loss of insured status), and 5552 persons with unknown reasons for losing their insured status.

Sex, age, year of enrollment in the health insurance union, enrollment period, and presence/absence of insured status in the union are shown in Table 1 for all cases subjected to analysis. We analyzed nondependent insured persons to guarantee gold standard-level accuracy in death information from enrollment data. Thus, both inpatients and outpatients comprised a relatively high proportion of males. The median enrollment duration in a health insurance union was 115 and 101 months for inpatients and outpatients, respectively. Inpatients and outpatients who lost their insured status between October 2012 and September 2015 numbered 796 (50.7\%) and 13, 042 (29.7\%), respectively. Of these, inpatients and outpatients who lost their insured status due to death numbered $473(30.1 \%)$ and 95 (0.2\%), respectively.

\section{Validation of claims-based definition of death}

Table 2 shows results of the validation of death based on claims, with health insurance enrollment data regarded as the gold standard. Regarding the definition using the information of discharge or disease status only (Definition 1, Table 2), the sensitivity, specificity, and PPV were $94.3 \%$ (446/473), $98.5 \%$ (1081/1098), and 96.3\% (446/463) for inpatients, and 47.4\% (45/95), 99.9\% (43, $773 / 43,775)$, and $95.7 \%$ (45/47) for outpatients, respectively. Among outpatients, regarding the definition using reimbursements for terminal care (Definition 2), the sensitivity, specificity, and PPV were $37.9 \%$ (36/95), 100.0\% (43,775/43,775), and $100.0 \%$ (36/36), respectively. Regarding the definition using the issuance of death certificates at home (Definition 3), the sensitivity, specificity, and PPV were $9.5 \%$ (9/95), 100.0\% (43,775/43,775), and $100.0 \%(9 / 9)$, respectively. When the reimbursement claims for the issuance of a death certificate and terminal care were combined with the disease status (Definition 4), the cases of death were identified with a sensitivity, specificity, and PPV of 54.7\% (52/95), 100.0\% $(43,775 / 43,775)$, and $100.0 \%(52 / 52)$, respectively.

\section{Discussion}

We examined usefulness and limitations of death information in claims and methods for improving the quality 
Table 1 Patient characteristics

\begin{tabular}{|c|c|c|c|c|c|c|}
\hline & \multicolumn{2}{|c|}{ Total $(N=45,441)$} & \multicolumn{2}{|c|}{ Inpatients $(N=1571)$} & \multicolumn{2}{|c|}{ Outpatients $(N=43,870)$} \\
\hline & N & $\%$ & N & $\%$ & N & $\%$ \\
\hline \multicolumn{7}{|l|}{ Sex } \\
\hline Male & 40,846 & 89.9 & 1500 & 95.5 & 39,346 & 89.7 \\
\hline Female & 4595 & 10.1 & 71 & 4.5 & 4524 & 10.3 \\
\hline \multicolumn{7}{|l|}{ Age, years } \\
\hline $65-69$ & 31,853 & 70.1 & 924 & 58.8 & 30,929 & 70.5 \\
\hline $70-74$ & 13,588 & 29.9 & 647 & 41.2 & 12,941 & 29.5 \\
\hline \multicolumn{7}{|c|}{ Number of claims issued in the most recent month } \\
\hline 1 & 32,084 & 70.6 & 1404 & 89.4 & 30,680 & 69.9 \\
\hline 2 or more & 13,357 & 29.4 & 167 & 10.6 & 13,190 & 30.1 \\
\hline \multicolumn{7}{|c|}{ Year of enrollment in a health insurance union } \\
\hline 2000 or earlier & 9282 & 20.4 & 337 & 21.5 & 8945 & 20.4 \\
\hline $2001-2005$ & 11,245 & 24.7 & 500 & 31.8 & 10,745 & 24.5 \\
\hline $2006-2010$ & 14,984 & 33.0 & 485 & 30.9 & 14,499 & 33.0 \\
\hline $2011-2015$ & 9930 & 21.9 & 249 & 15.8 & 9681 & 22.1 \\
\hline Enrollment period, months (median) & 89 & & 115 & & 101 & \\
\hline \multicolumn{7}{|l|}{ Union enrollment status } \\
\hline Continued enrollment & 31,603 & 69.5 & 775 & 49.3 & 30,828 & 70.3 \\
\hline Loss of insured status & 13,838 & 30.5 & 796 & 50.7 & 13,042 & 29.7 \\
\hline \multicolumn{7}{|l|}{ Reason for loss of insured status } \\
\hline Retirement & 6723 & 14.8 & 176 & 11.2 & 6547 & 14.9 \\
\hline Relocation & 104 & 0.2 & 2 & 0.1 & 102 & 0.2 \\
\hline Unpaid insurance fees & 1130 & 2.5 & 12 & 0.8 & 1118 & 2.5 \\
\hline Other & 5313 & 11.7 & 133 & 8.5 & 5180 & 11.8 \\
\hline Death & 568 & 1.2 & 473 & 30.1 & 95 & 0.2 \\
\hline
\end{tabular}

of death information for aged persons. For inpatients, both the sensitivity (94.3\%) and specificity (98.5\%) of death information in the claims were high. Among outpatients, however, the specificity was high (99.9\%), but the sensitivity was low (47.4\%) (Table 2). The addition of reimbursement claims for terminal care or the issuance of a death certificate at home to the definition of death, followed by the termination of subsequent health insurance claims, still indicated low sensitivity (54.7\%) (Table 2).

Despite developments in health insurance claims databases, the quality of death information in claims is not guaranteed because those data are collected primarily for reimbursement. A previous validation study using the claims data in Japan between January 2005 and

Table 2 Sensitivity and specificity of the claims-based definition of death

\begin{tabular}{|c|c|c|c|c|c|c|c|c|c|c|c|c|}
\hline \multirow{2}{*}{$\begin{array}{l}\text { Definition } \\
\text { Inpatients }\end{array}$} & \multirow[t]{2}{*}{ Description } & \multirow[t]{2}{*}{ Total } & \multirow[t]{2}{*}{$\begin{array}{l}\text { True } \\
\text { positive }\end{array}$} & \multirow[t]{2}{*}{$\begin{array}{l}\text { False } \\
\text { positive }\end{array}$} & \multirow[t]{2}{*}{$\begin{array}{l}\text { False } \\
\text { negative }\end{array}$} & \multirow[t]{2}{*}{$\begin{array}{l}\text { True } \\
\text { negative }\end{array}$} & \multicolumn{2}{|c|}{ Sensitivity } & \multicolumn{2}{|c|}{ Specificity } & \multicolumn{2}{|c|}{$\begin{array}{l}\text { Positive predictive } \\
\text { value (PPV) }\end{array}$} \\
\hline & & & & & & & & & & & & \\
\hline 1 & Death as discharge status & 1571 & 446 & 17 & 27 & 1081 & 94.3 & {$[92.2-96.4]$} & 98.5 & {$[97.7-99.2]$} & 96.3 & [94.6-98.0] \\
\hline \multicolumn{13}{|c|}{ Outpatients } \\
\hline 1 & Death as disease status & 43,870 & 45 & 2 & 50 & 43,773 & 47.4 & {$[37.3-57.4]$} & 99.9 & [99.9-100.0] & 95.7 & [90.0-100.0] \\
\hline 2 & $\begin{array}{l}\text { Terminal care at home }+ \\
\text { claims terminated }\end{array}$ & 43,870 & 36 & 0 & 59 & 43,775 & 37.9 & {$[28.1-47.7]$} & 100.0 & [100.0-100.0] & 100.0 & [100.0-100.0] \\
\hline 3 & $\begin{array}{l}\text { Death certificate }+ \\
\text { claims terminated }\end{array}$ & 43,870 & 9 & 0 & 86 & 43,775 & 9.5 & {$[3.6-15.4]$} & 100.0 & [100.0-100.0] & 100.0 & [100.0-100.0] \\
\hline 4 & 1 or 2 or 3 & 43,870 & 52 & 0 & 43 & 43,775 & 54.7 & {$[44.7-64.7]$} & 100.0 & [100.0-100.0] & 100.0 & [100.0-100.0] \\
\hline
\end{tabular}


August 2009 reported that the sensitivity of death was limited [13]. The increase in validity among inpatients compared with the previous study may be due to policies promoting digitization, such as the obligation to submit health insurance claims online starting in 2011 [16]. Differences in inpatient characteristics between the 2 study populations (20-74 years in Ooba et al.'s study [13] and 65-74 years in our study) also likely contributed to the discrepancy in the results. On the other hand, validity among outpatients still remained low compared with the previous study [13]. Possible reasons for the low sensitivity of outpatient death are attributable to the nature of claims. Because health insurance claims data are collected primarily for reimbursement, medical institutions are not motivated to record deaths in claims, and thus, the omission of recording of death is possible. Additionally, there is no system to follow patients' prognoses and reflect them in the claims database.

Our study contributed to promote epidemiological research using claims database by increasing understanding for the limitation and usefulness of data. Specificity of death information for both inpatients and outpatients was high, and thus, the overestimation of the number of death due to misclassification of outcomes, that is, researchers misclassify survivors as decedents, is low. High sensitivity of inpatient deaths suggests the potential usefulness for identifying death. The risk of the misclassification of outcomes, that is, researchers misclassify deceased persons as being alive due to the absence of a record of death in the claims, is low. However, it should be noted that $5.7 \%$ of deceased persons are possibly misclassified. Given the low sensitivity for outpatient deaths, there is a distinct limitation for identifying death from claims data. Although we also examined methods for increasing the sensitivity of death information by combining disease status and charge data recorded in claims (when death was defined solely by disease status or together with charge records of terminal care), the sensitivity for identifying deaths is still limited. Currently, we recommend not using death information obtained solely from records in outpatient claims. These findings should be known among researchers and health insurance societies when they use claims data.

This study possessed some limitations. Regarding the generalization of our results, the target population comprised nondependent insured persons aged 65-74 years enrolled in workplace health insurance; thus, our results may not be applicable to all aged persons. Moreover, subjects were enrolled in health insurance unions insuring a fraction of all large companies. We did not include subjects enrolled in health insurance unions targeting medium-sized to small businesses, seamen, public employees, self-employed individuals, and individuals covered by the Medical Insurance System for individuals $\geq 75$ years. Finally, although the PPV depends on the prevalence (i.e., prior probability of death) of the study population, we know little about the prevalence of our study population. Therefore, our findings cannot be applied to the claims data of all aged persons. Nevertheless, the claims database used in the present study represents the best available current data because validation to identify death in aged persons could be performed by the direct linkage of health insurance claims and health insurance enrollment data.

\section{Conclusions}

We examined usefulness and limitations of using death information in claims databases and examined methods to improve the quality of death information for aged persons. High sensitivity and specificity of death information in inpatient claims suggested the potential utility of identifying death. However, given the low sensitivity for outpatient deaths, the use of death information obtained solely from records in outpatient claims is not recommended.

\section{Abbreviations}

BiDAME: Big Data Analysis of Medical care for the Elderly in Kyoto; NDB: National Database of Health Insurance Claims and Specific Health Checkups of Japan

\section{Acknowledgements \\ This work was supported by the Ministry of Health, Labour and Welfare Grant-in-Aid for Scientific Research (Research on Policy Planning and Evalu- ation) (H27-policy-strategy-013), the Institute for Health Economics and Policy (Grant for Young Researcher B, H28), and the Ministry of Health, Labour and Welfare Grant-in-Aid for Scientific Research (Research on Policy Planning and Evaluation) (H29-policy-strategy-005).}

\section{Authors' contributions}

MS contributed to analyze data and write the manuscript. SO contributed to analyze data, interpret the results, and write the manuscript. TI contributed to make a structure of database setting to analyze, interpret the results, and write the manuscript. YN contributed to collect the data, interpret the results, and review the manuscript. GK contributed to collect the data, interpret the results, and review the manuscript. YT contributed to collect the data, analyze data, and review the manuscript. TN contribute to make a plan of this research and general management of this research to carry out, and all other BiDAME members will join discussion for interpretation of the results, review, management of research progress, setting up the technical environment to analyze database and contribute to analyze data. All authors read and approved the final manuscript.

\section{Authors' information}

Members of BiDAME (Big Data Analysis of Medical care for the Elderly in Kyoto): Funakoshi T, Goto Y, Goto E, Hanaki N, Hiragi S, Ikenoue T, Iwao T, Kawakami K, Kondo N, Kunisawa S, Mori Y, Nakatsui M, Neff Y, Ohtera S, Okamoto K, Otsubo T, Saito H, Saito Y, Sakai M, Sato I, Seto K, Shimizu S, Takahashi Y, Yamashita K, Yoshida S, in Kyoto University Hospital / Kyoto University School of Public Health, Kyoto, JAPAN

\section{Funding}

This work was supported by the Ministry of Health, Labour and Welfare Grant-in-Aid for Scientific Research (Research on Policy Planning and Evaluation) (H27-policy-strategy-013), the Institute for Health Economics and Policy (Grant for Young Researcher B, H28), and the Ministry of Health, Labour and Welfare Grant-in-Aid for Scientific Research (Research on Policy Planning and Evaluation) (H29-policy-strategy-005). 


\section{Availability of data and materials}

Not applicable

\section{Ethics approval and consent to participate}

This study complies with the "Ethical guidelines for epidemiological research" of the Ministry of Health, Labor and Welfare of Japan. This study has been reviewed and approved by a Ministry of Health, Labor and Welfare panel of experts and approved by the Kyoto University medical ethics committee (reference number: R0635).

We used unlinkable anonymized data, and individuals cannot be identified. The data obtained in this study were not used for purposes other than this study and data sharing not applicable. This study is an observational study using existing data, and matters of advantage or disadvantage to research participants, or that cause new invasion or adverse events to research participants, do not apply.

\section{Consent for publication}

This study used unlinkable anonymized data, and individuals cannot be identified.

\section{Competing interests}

The authors declare that they have no competing interests. Declarations of $\mathrm{COI}$ from each researcher are managed by Kyoto University and Kyoto University Hospital.

\section{Author details}

'Department of Health Informatics, Kyoto University School of Public Health, Yoshidakonoe-cho, Sakyo-ku Kyoto 606-8501, Japan. ²Division of Medical Information Technology and Administration Planning, Kyoto University Hospital, 54 Kawahara-cho, Shogoin, Sakyo-ku Kyoto 606-8507, Japan. ${ }^{3}$ Department of Research, Institute for Health Economics and Policy, Tokyo, Japan. ${ }^{4}$ Solutions Center for Health Insurance Claims, Kyoto University Hospital, 54 Kawahara-cho, Shogoin, Sakyo-ku Kyoto 606-8507, Japan.

Received: 8 May 2019 Accepted: 23 September 2019

Published online: 23 November 2019

\section{References}

1. United Nations, Department of Economic and Social Affairs, Population Division. World population prospects: the 2017 revision 2017 [Available from: https://esa.un.org/unpd/wpp/Publications/Files/WPP2017_ KeyFindings.pdf

2. Research NloPaSS. Population projections for Japan (January 2012) -2011 to 2060- 2012 [Available from: http://www.ipss.go.jp/site-ad/index_english/ esuikei/gh2401e.asp.

3. Fukawa T. Inpatient expenditure of the decedent elderly in Japan. Br J Med Med Res. 2016;15(10):1-10.

4. Chen B, Kuo CC, Huang N, Fan VY. Reducing costs at the end of life through provider incentives for hospice care: a retrospective cohort study. Palliat Med. 2018;32(8):1389-400.

5. Kim SH, Kang S, Song MK. Intensity of care at the end of life among older adults in Korea. J Palliat Care. 2018;33(1):47-52

6. Milea $D$, Azmi $S$, Reginald $P$, Verpillat $P$, Francois $C$. A review of accessibility of administrative healthcare databases in the Asia-Pacific region. J Mark Access Health Policy. 2015;3.

7. Lai EC, Man KK, Chaiyakunapruk N, Cheng CL, Chien HC, Chui CS, et al. Brief report: databases in the Asia-Pacific region: the potential for a distributed network approach. Epidemiology. 2015;26(6):815-20.

8. Kim JA, Yoon S, Kim LY, Kim DS. Towards actualizing the value potential of Korea Health Insurance Review and Assessment (HIRA) data as a resource for health research: strengths, limitations, applications, and strategies for optimal use of HIRA data. J Korean Med Sci. 2017;32(5):718-28.

9. Hsing AW, loannidis JP. Nationwide population science: lessons from the Taiwan National Health Insurance Research Database. JAMA Intern Med. 2015;175(9):1527-9.

10. Aljunid SM, Srithamrongsawat S, Chen W, Bae SJ, Pwu RF, Ikeda S, et al. Health-care data collecting, sharing, and using in Thailand, China mainland, South Korea, Taiwan, Japan, and Malaysia. Value Health. 2012; 15(1 Suppl):S132-8.

11. As PENc, Andersen M, Bergman U, Choi NK, Gerhard T, Huang C, et al. The Asian Pharmacoepidemiology Network (AsPEN): promoting multi-national collaboration for pharmacoepidemiologic research in Asia. Pharmacoepidemiol Drug Saf. 2013:22(7):700-4

12. Saokaew S, Sugimoto T, Kamae I, Pratoomsoot C, Chaiyakunapruk N. Healthcare databases in Thailand and Japan: potential sources for health technology assessment research. PLoS One. 2015;10(11):e0141993.

13. Ooba N, Setoguchi S, Ando T, Sato T, Yamaguchi T, Mochizuki M, et al. Claims-based definition of death in Japanese claims database: validity and implications. PLoS One. 2013;8(5):e66116.

14. Nakayama T, Imanaka Y, Okuno Y, Kato G, Kuroda T, Goto R, et al. Analysis of the evidence-practice gap to facilitate proper medical care for the elderly: investigation, using databases, of utilization measures for National Database of Health Insurance Claims and Specific Health Checkups of Japan (NDB). Environ Health Prev Med. 2017;22(1):51.

15. Kimura S, Sato T, Ikeda S, Noda M, Nakayama T. Development of a database of health insurance claims: standardization of disease classifications and anonymous record linkage. J Epidemiol. 2010;20(5):413-9.

16. Ministry of Health, Labour and Welfare. Status of digitization of electronic healthcare claim, etc. (for medical care in April 2015) 2015 [Available from: http://www.mhlw.go.jp/stf/seisakunitsuite/bunya/0000099015.html.

\section{Publisher's Note}

Springer Nature remains neutral with regard to jurisdictional claims in published maps and institutional affiliations.

\section{Ready to submit your research? Choose BMC and benefit from:}

- fast, convenient online submission

- thorough peer review by experienced researchers in your field

- rapid publication on acceptance

- support for research data, including large and complex data types

- gold Open Access which fosters wider collaboration and increased citations

- maximum visibility for your research: over $100 \mathrm{M}$ website views per year

At BMC, research is always in progress.

Learn more biomedcentral.com/submissions 